\title{
IMPACT OF SEA-SURFACE TEMPERATURE ANOMALIES IN THE EQUATORIAL INDIAN OCEAN AND WESTERN PACIFIC ON THE ASIAN SUMMER MONSOON IN THREE GENERAL CIRCULATION MODELS
}

\author{
P. TSCHUCK,,${ }^{\mathrm{a}, *}$ F. CHAUVIN, ${ }^{\mathrm{b}}$ B. DONG ${ }^{\mathrm{c}}$ and K. ARPE ${ }^{\mathrm{a}}$ \\ a Max-Planck-Institut für Meteorologie, Hamburg, Germany \\ b Centre National de la Recherche Météorologique, Toulouse, France \\ ${ }^{\mathrm{c}}$ Department of Meteorology, University of Reading, Reading, UK \\ Received 21 October 1999 \\ Revised 21 October 2003 \\ Accepted 21 October 2003
}

\begin{abstract}
The sensitivities of the Asian summer monsoon to sea-surface temperature (SST) anomalies in the equatorial Indian Ocean and the western Pacific are compared in three different general circulation models (ARPËGE, ECHAM, UGAMP). The impacts to idealized anomalies of $1 \mathrm{~K}$ show common features, notably a weaker monsoon for warm equatorial Indian Ocean SSTs. For a warm western Pacific, the impact over India shows a dipole structure with increases in the southern part and decreases in the northern part for the ECHAM and UGAMP models, with ARPËGE showing a different response. The models also disagree on the linearity of the impact. The response to cold anomalies is nearly the same, with opposite sign, as for warm anomalies in the ECHAM model but is non-linear in the ARPËGE and UGAMP models. The study underlines the need for accurate measurements of the regional SSTs, which are as equally important for local rainfall as the remote large-scale impact from the El Niño-Southern Ocean oscillation. Copyright (C) 2004 Royal Meteorological Society.
\end{abstract}

KEY WORDS: Asian monsoon; sea surface temperature; climate modelling

\section{INTRODUCTION}

The atmospheric model intercomparison project (AMIP) has shown that there is a large spread of the Asian summer monsoon characteristics among the participating general circulation models (GCMs) (Sperber and Palmer, 1996; Gadgil et al., 1998). This spread is largely attributable to biases in the parameterizations of land surface processes and convection. Differences in the mean monsoon have also been noted in different reanalyses by Annamalai et al. (1999). It has been suggested that the intense interactions between the dynamics and diabatic processes over the Indian subcontinent make it intrinsically difficult for the models to capture the right probability density function of the principal component of precipitation (Palmer, 1994). In this picture of the monsoon, land surface and SST anomalies are thought to change the shape of the probability density function, yielding some potential predictability. Rodwell and Hoskins (1995) have pointed out that breaks of the southwest monsoon are often related to disturbances in the southern Indian Ocean, which adds to the difficulties in achieving good forecasts.

More specifically, Soman and Slingo (1997) investigated the impact of SST anomalies on the monsoons of 1983, 1984 and 1994. They found that warm anomalies in the western Pacific enhance the tropical convective maximum and lead to an early onset of the monsoon. Similarly, anomalies in the Indian Ocean can have an impact on the strength of the monsoon (Chandrasekar and Kitoh, 1998). Arpe et al. (1998) identified the

* Correspondence to: P. Tschuck, Institute for Atmospheric and Climate Science ETH, Winterthurerstr. 190, CH-8057 Zurich, Switzerland; e-mail: tschuck@iac.umnw.ethz.ch 
northern Indian Ocean as a region where small anomalies on the order of the uncertainty of the measurements can have an impact on the precipitation in India. They also confirmed teleconnections of all-India rainfall (AIR) with SSTs in the western Pacific and very weak ones in the equatorial Indian Ocean.

Strong minus weak AIR composites show relatively small differences in SSTs. On the other hand, imposing SSTs has a strong effect. Two arguments might explain this puzzling situation. The response often has some subcontinental-scale pattern over India and large AIR summers are also often the result of a very strong monsoon in only some parts of the subcontinent. Secondly, the large sensitivity to SST anomalies also implies that small anomalies can have a strong impact. The following will assess whether this large sensitivity is a peculiarity of the ECHAM model or whether similar sensitivies are found in other GCMs as well.

\section{MODELS AND EXPERIMENTAL SETUPS}

Results from three different models are considered in the following. They all use the spectral method of the European Centre for Medium-Range Weather Forecast (ECMWF) model to solve for the advection and are operated at a medium resolution of T31 (ARPÈGE) and T42 (ECHAM and UGAMP). While the dynamics are similar for the three models, they differ in the parameterizations of diabatic processes and in their orographies (ARPËGE and ECHAM have mean orography; UGAMP uses an envelope orography).

SST anomalies of $\pm 1 \mathrm{~K}$ are imposed in the western Pacific $\left(10-20^{\circ} \mathrm{N}, 110-160^{\circ} \mathrm{E}\right)$ and separately in the equatorial Indian Ocean $\left(5^{\circ} \mathrm{S}-5^{\circ} \mathrm{N}, 50-100^{\circ} \mathrm{E}\right)$. These two regions have been agreed on in the EU-project SHIVA (Studies of the hydrology, influence and variability of the Asian summer monsoon). Correlations between AIR and June-September SSTs are relatively high in these regions (Annamalai et al., 1999). The magnitude of $1 \mathrm{~K}$ is on the order of the observed anomalies of the boreal summer mean temperatures in the specified regions. Ensembles of nine (ARPÈGE) and six (ECHAM and UGAMP) monsoon seasons are collected for the evaluation.

\subsection{ARPÈGE}

ARPÈGE-Climat is a modular state-of-the-art spectral climate model developed from the weather forecasting model ARPĖGE-IFS operationally employed at Météo-France and ECMWF (Déqué et al., 1994). The version of the model used in this set of experiments is the cycle 16c, which includes the statistical cloud scheme of Ricard and Royer (1993) and the semi-Lagrangian scheme. The cumulus convection is parameterized by the mass-flux scheme of Bougeault (1985). It uses a Kuo-type closure, and requires both low-level large-scale moisture convergence and conditional instability of the temperature profile for convection to occur.

An ensemble of nine members for each case is performed by starting the model from initial conditions separated by 5 days from 23 February to 4 April of a previous experiment. The SST anomalies were added to a climatological SST field issued from the AMIP period (1979-88).

\section{2. ЕСHAM}

The experiments of this study have been performed with the ECHAM4.5 model, i.e. the version that participates in the AMIP II intercomparison. The modifications from the standard ECHAM4 (Roeckner et al., 1996) include implicit treatment of the land surface temperature (Schulz, 1998), more realistic orography, and tuning of cloud and convective parameters. The main improvements of the modifications are a stronger Indian monsoon and more realistic zonal mean winds in the tropical upper troposphere. ECHAM4.5 uses the Tiedtke (1989) convection scheme, but with a closure based on the convective available potential energy.

A sample of six monsoon seasons is collected for each of the four cases. This is done by restarting the model at 1 April of six different years from a control simulation with climatological mean SSTs. This approach yields an ensemble that contains some spread in the land-surface initial conditions, which is not the case when the ensemble members are started from consecutive days of the same year. The resolution of the experiments is T42 on 19 levels, sufficient to capture the Indian monsoon (Stephenson et al., 1998). Higher resolution, of 
course, captures depressions and the monsoon trough with finer detail, and improvements were indeed found in a T106 experiment with the standard ECHAM4 (Stendel and Roeckner, 1998).

\subsection{UGAMP}

The UK Universities model is also based on the ECMWF model. It uses the Betts and Miller (1993) convection, which adjusts the convective heating and moistening profiles to reference profiles. A no-flux boundary condition is specified at the bottom of the soil, which improves the simulation of the Asian summer monsoon compared with prescribed deep soil temperature and moisture (Dong and Valdes, 1998). Other aspects of the model are described in Slingo et al. (1994).

The six member ensembles for each sensitivity experiment have been made by restarting the model from initial conditions taken from 27 March to 1 April of the last year of the control run. The control simulation is an 11year simulation with the climatological AMIP SSTs.

\section{MEAN MONSOON}

The Asian summer monsoon has some unique characteristics, such as the lower tropospheric southwesterly jet over the Arabian Sea, the upper tropospheric easterlies over the Indian Ocean, the Tibetan anticyclone, and copious rainfall over parts of the Asian continent. Figure 1 shows model performance in terms of mean June to September precipitation. Compared with the merged observational estimate of the Global Precipitation Climatology Project (GPCP; Huffman et al., 1997), the models tend to simulate larger precipitation maxima. The UGAMP model, in particular, simulates large precipitation values at a few grid points in the Himalayas and close to the equator. ARPĖGE and ECHAM are better in this respect, but they overestimate precipitation
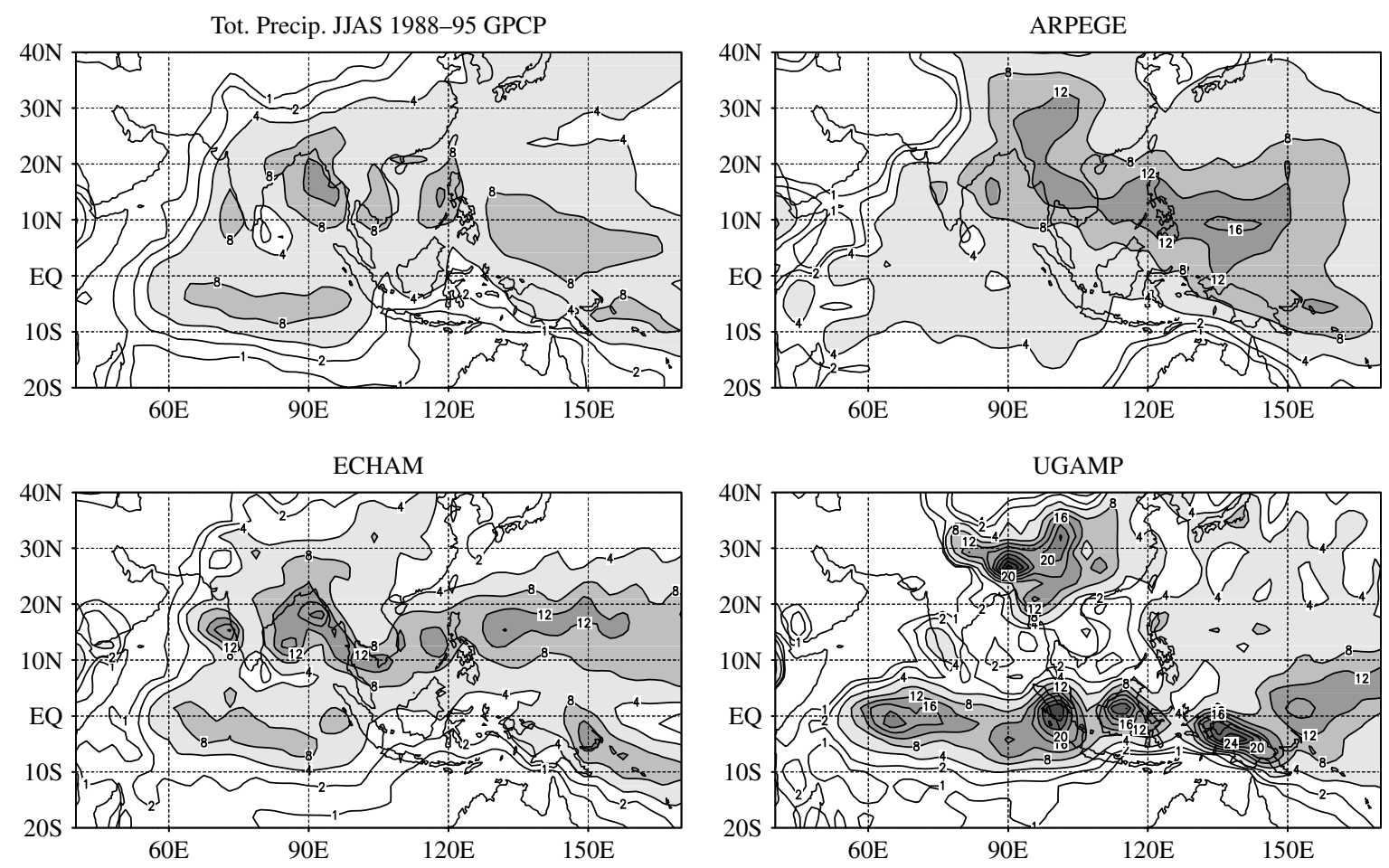

Figure 1. Mean June to September total precipitation $\left(\mathrm{mm} \mathrm{day}^{-1}\right)$ of the GPCP observational estimate, the ARPËGE, the ECHAM, and the UGAMP model. Contours at $1,2,4,8,12, \ldots \mathrm{mm}$ day ${ }^{-1}$, with shading above $4 \mathrm{~mm} \mathrm{day}^{-1}$ 

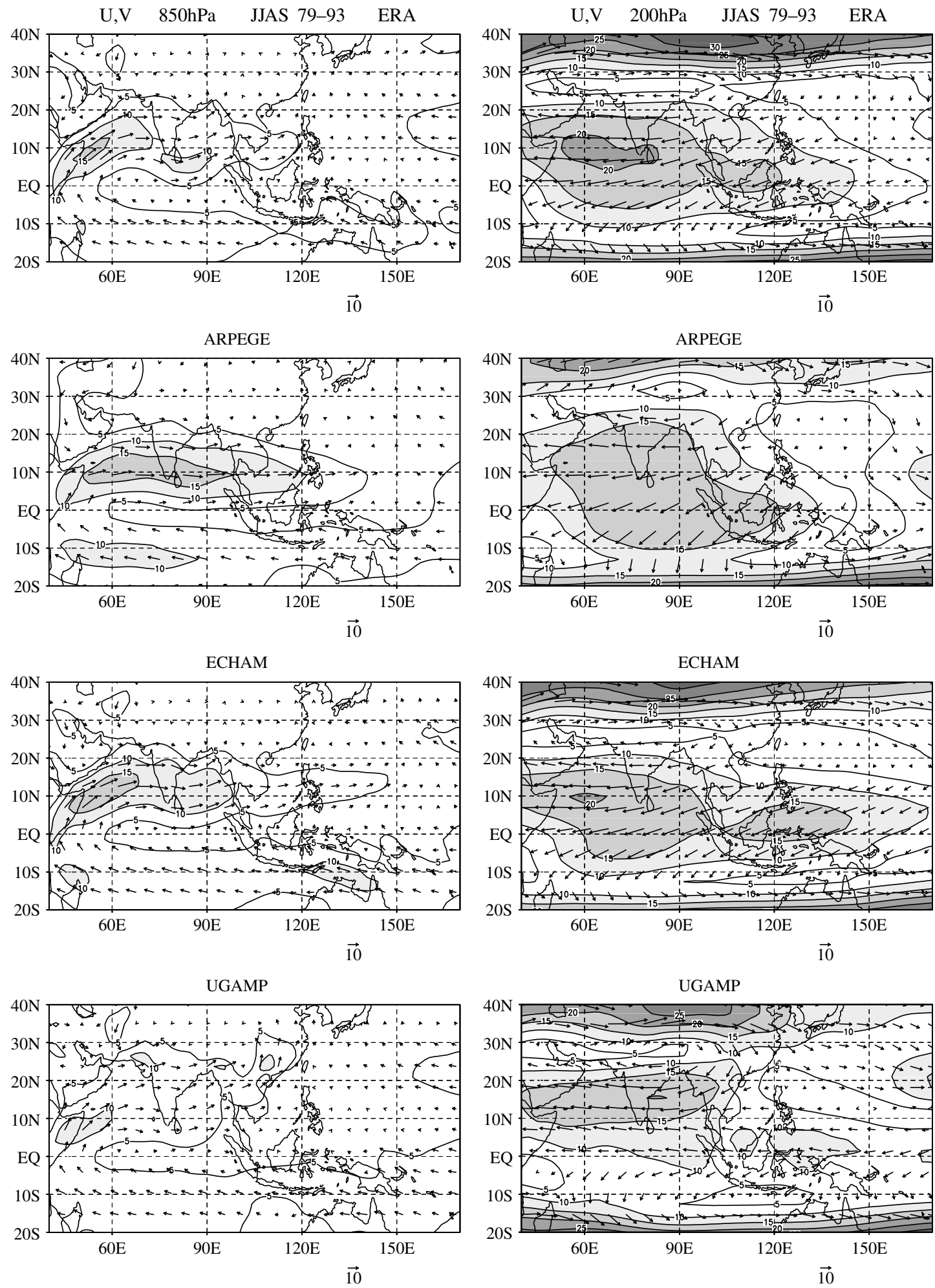

Figure 2. Mean June to September wind at $850 \mathrm{hPa}$ (left) and $200 \mathrm{hPa}$ (right) of the ECMWF reanalyses of 1979-93, the ARPÈGE, the ECHAM, and the UGAMP models 
in the western Pacific. Over India, the UGAMP model is too dry, ARPÈGE is too dry in the northwestern part only, and ECHAM is slightly too wet.

Figure 2 shows the circulation at $850 \mathrm{hPa}$ and $200 \mathrm{hPa}$ averaged over June to September for the three models and the ECMWF reanalyses. At $850 \mathrm{hPa}$, the T31 version of the ARPĖGE model overestimates the westerlies over India and the Bay of Bengal. ECHAM also has a westerly bias to the east of $70^{\circ} \mathrm{E}$, whereas the UGAMP model underestimates the monsoon circulation and has a southerly bias over China. At $200 \mathrm{hPa}$, the models slightly underestimate the tropical easterly jet.

\section{MEAN ATMOSPHERIC RESPONSE}

\subsection{Western Pacific anomaly}

The anomaly patterns of precipitation for the western Pacific cases are shown in Figure 3. For a warm western Pacific, strongly enhanced precipitation is found over the region itself. There is less precipitation to the
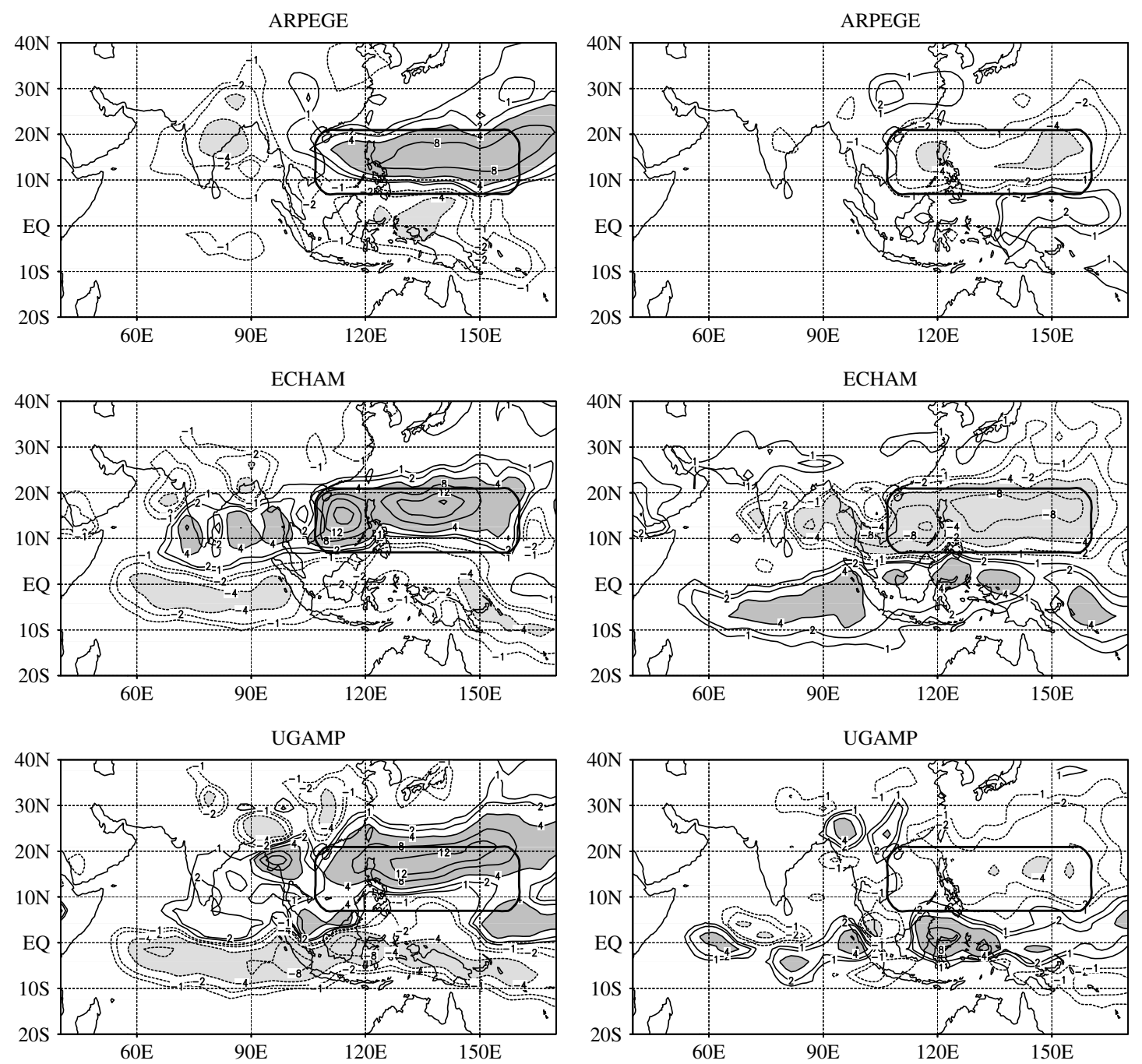

Figure 3. Precipitation anomalies for a $1 \mathrm{~K}$ warm (left)/cold (right) anomaly in the western Pacific. Contours at \pm 1 , 2, 4, 8, $12, \ldots \mathrm{mm}$ day $^{-1}$. Light shading below $-4 \mathrm{~mm}$ day $^{-1}$, darker shading above $4 \mathrm{~mm}^{\text {day }}{ }^{-1}$ 
south of the warm region in the three models. To the west of the anomaly region, the models agree on reduced precipitation in Bangladesh and northeastern India. Over southern India, ECHAM and UGAMP simulate a stronger monsoon, whereas the ARPÈGE model gives less precipitation over almost all parts of India. In the ECHAM and UGAMP simulations, a strong reduction of precipitation is found in the equatorial Indian Ocean. The reduction is smaller for the ARPËGE model, which simulates less precipitation in the oceanic convergence zone (Figure 1). The sensitivity is much larger for the UGAMP model, which has copious rain just south of the equator in the control run.

The impact for a cold anomaly in the western Pacific is generally smaller than the response to a warm anomaly, except for the ECHAM model, which shows a rather large sensitivity also for a cold anomaly.
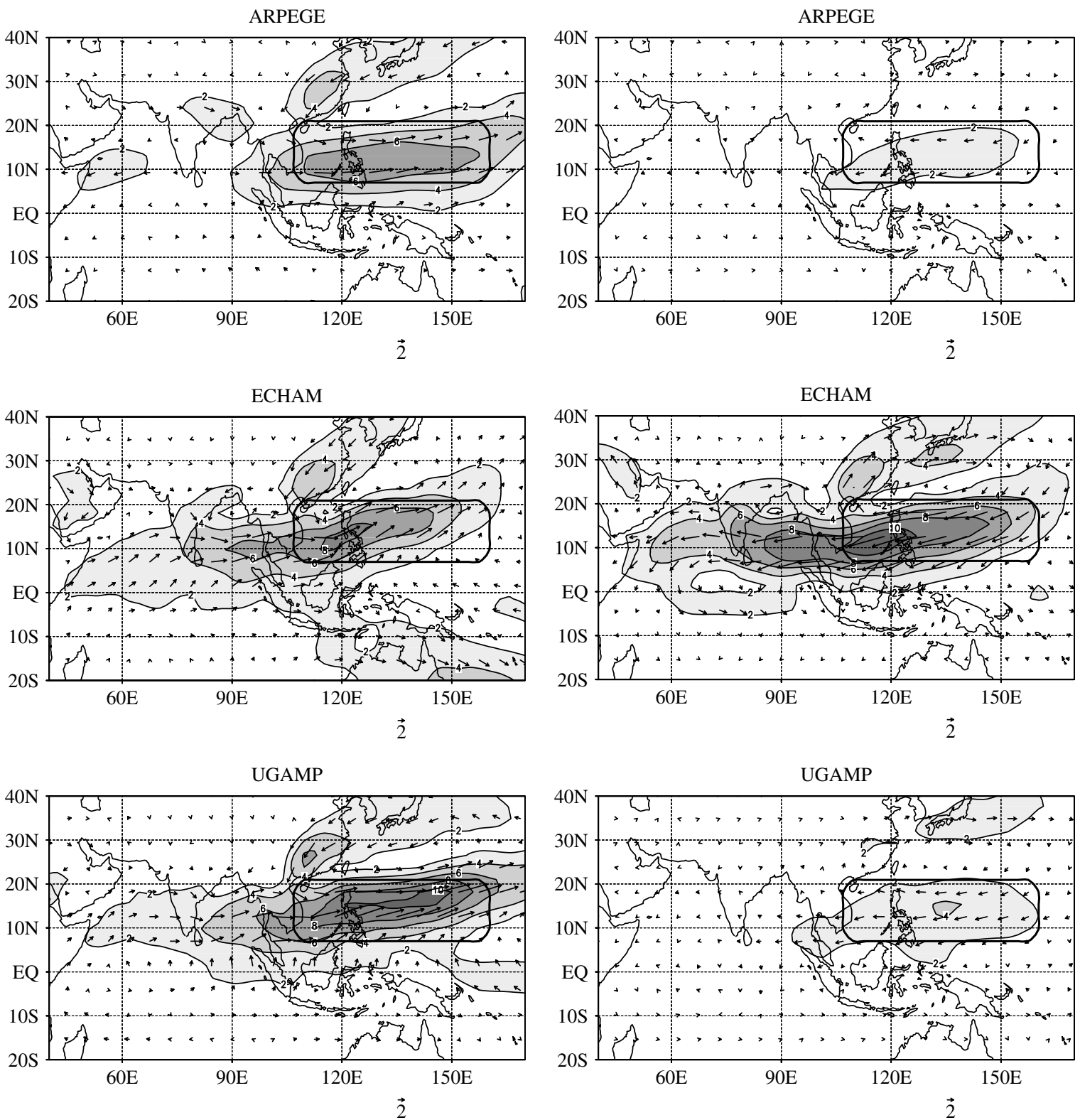

Figure 4. Wind anomalies at $850 \mathrm{hPa}$ for a $1 \mathrm{~K}$ warm (left)/cold (right) anomaly in the western Pacific. Wind speed anomalies shaded increasingly from $2 \mathrm{~m} \mathrm{~s}^{-1}$ onwards 
This contrasting behaviour might be due to the overestimation of precipitation over the western Pacific in the mean monsoon of ECHAM. The precipitation changes for this model are almost the same as those of the warm anomaly case, but with opposite sign. A north-south dipole with positive precipitation anomalies in the northern parts and negative anomalies in the southern parts is simulated over India. Large positive anomalies are found to the south of the cold region and in the equatorial Indian Ocean. In the ARPÈGE simulation, the reduced precipitation values over the cold region itself are accompanied by positive anomalies to the northwest and southeast of the region. UGAMP is similar, but with more pronounced changes in the equatorial Indian Ocean.

The ensemble mean impact on the $850 \mathrm{hPa}$ winds is shown in Figure 4. The largest response is found in the UGAMP model for a warm western Pacific and in ECHAM for a cold western Pacific. A common feature of all three simulations is the anomalous northeasterlies over China, indicating a weakened East Asian monsoon for a warm western Pacific. Over the warm region itself, the westerlies are stronger by $6-10 \mathrm{~m} \mathrm{~s}^{-1}$. In the
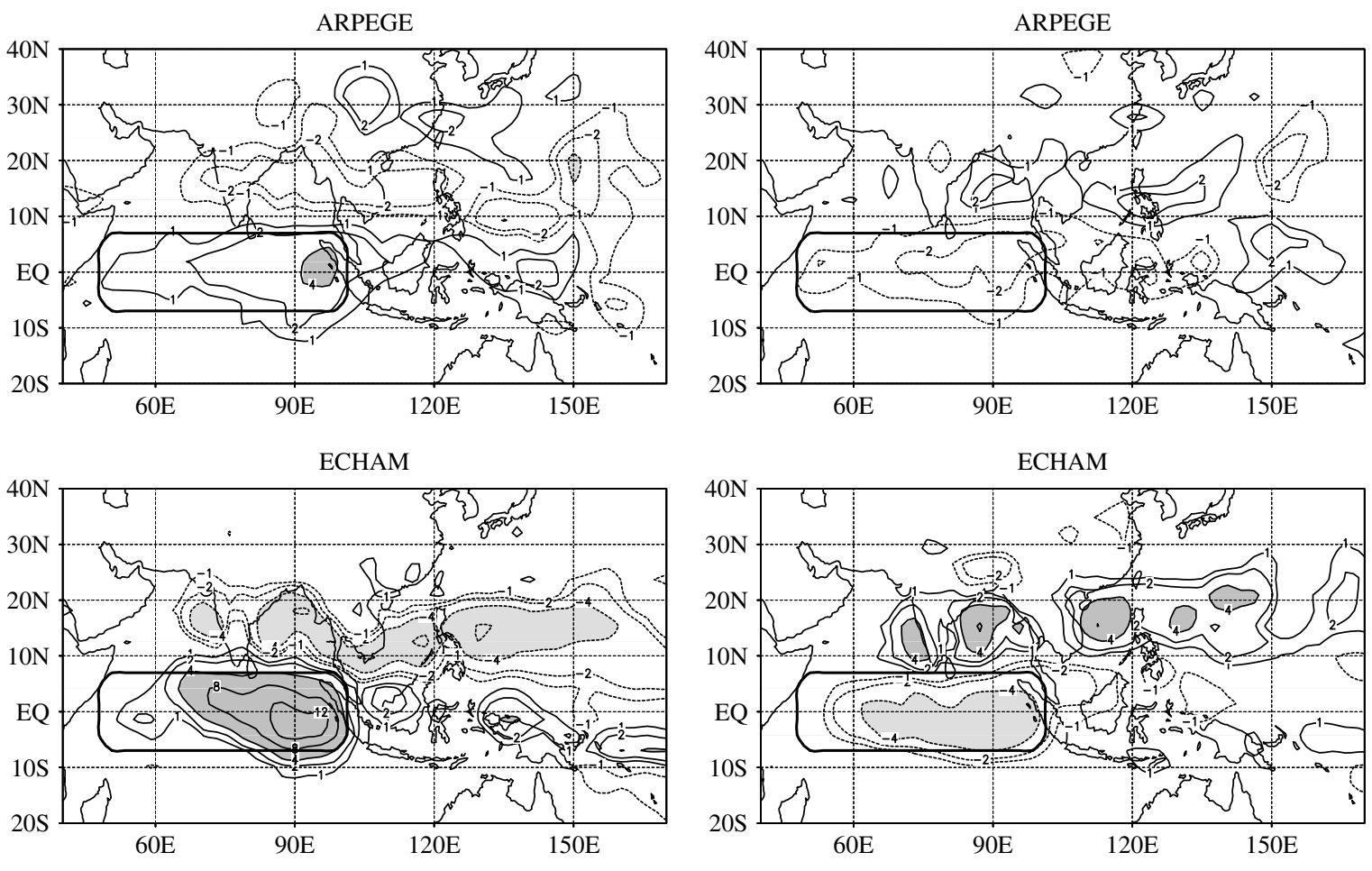

UGAMP
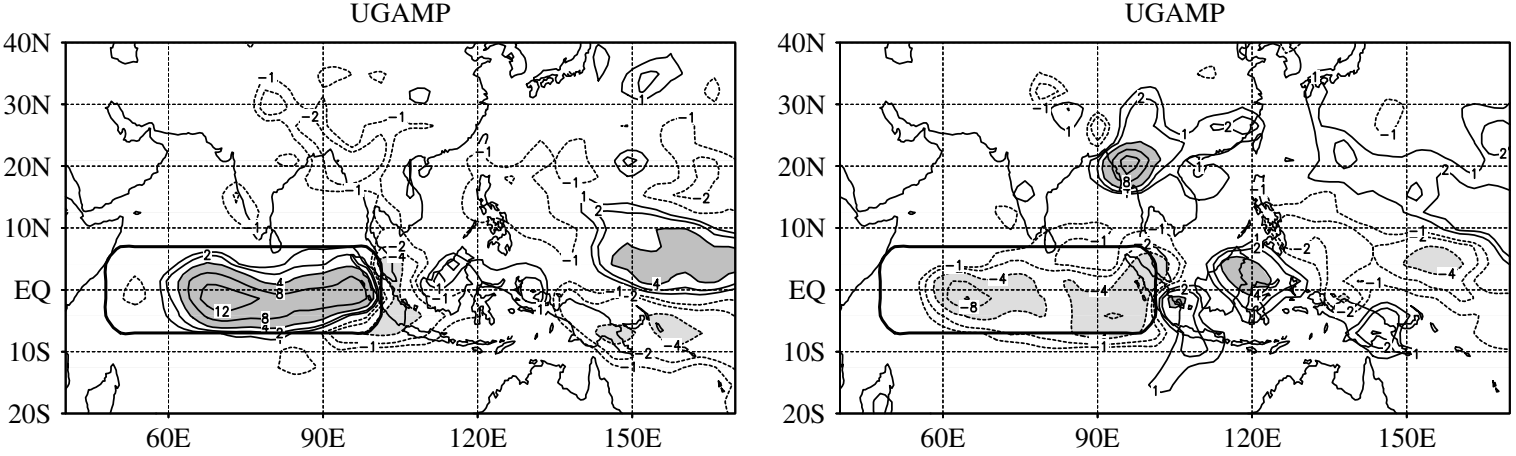

Figure 5. Precipitation anomalies for a $1 \mathrm{~K}$ warm (left)/cold (right) anomaly in the equatorial Indian Ocean. Contours at $\pm 1,2$, 4, 8 , $12, \ldots \mathrm{mm}$ day $^{-1}$. Light shading below $-4 \mathrm{~mm}$ day $^{-1}$, darker shading above $4 \mathrm{~mm}^{\text {day }}{ }^{-1}$ 
ECHAM and UGAMP models the increased westerlies extend westwards over India and into the Arabian Sea, consistent with the precipitation pattern of Figure 3.

For a cold anomaly of $1 \mathrm{~K}$, the ARPĖGE and UGAMP models simulate relatively small anomalies. The ECHAM model, on the other hand, shows a strongly reduced monsoon circulation over the whole domain for a cold western Pacific. The reduction of the westerlies is even stronger than the increase for a warmer western Pacific.

\subsection{Equatorial Indian Ocean anomaly}

A large sensitivity of the precipitation patterns is also found for anomalous SSTs in the equatorial Indian Ocean. For the warm Indian Ocean case, the models show a strong increase of the precipitation over the warmer region itself (Figure 5). However, the increase is confined to the eastern part of the box; only moderate increases are simulated in the western part, which is under the Somali jet. Negative precipitation anomalies are found to the north of the warm region over India in all three models. These negative anomalies extend eastward into the western Pacific. Generally, the same patterns, but with reversed sign, are simulated for a cold anomaly. Strong decreases over the equator are accompanied by increases in the northern convergence zone. One notable exception from this linear behaviour is the negative anomalies in India for the ARPËGE model.

The strong sensitivity of the ECHAM model to Indian Ocean SSTs is also displayed by the wind anomalies in Figure 6. The wind anomalies at $850 \mathrm{hPa}$ are comparatively small in the ARPËGE and UGAMP models. Convergence is simulated over the eastern part of the warm region. To the north, a reduced monsoon circulation occurs for warm SSTs, with the strongest reduction of the westerlies over the Bay of Bengal and the southern South China Sea. For cold SST anomalies, the westerlies over India and Indochina are stronger than in the control simulations.

\section{CONCLUSIONS}

The impacts of idealized SST anomalies in the western Pacific and the equatorial Indian Ocean on the Asian summer monsoon have been compared in three models. Despite large differences in the simulation of the mean monsoon, the models agree on a mitigation of the monsoon for a warm equatorial Indian Ocean. This result was also found by Chandrasekar and Kitoh (1998). They interpreted the reduction of precipitation in India as a favouring of the oceanic tropical convergence zone (TCZ) over the continental TCZ for a warm anomaly. An examination of the observed SST anomalies in the equatorial Indian Ocean, however, shows no clear reduction of the AIR with increasing temperatures. Figure 7 displays a scatter plot of the AIR data of Parthasarathy et al. (1994) against June-August temperatures of the GISST2.2 data in the equatorial Indian Ocean region for the years 1903 to 1994. Also shown are the ensemble members of the ECHAM simulations, which use the optimally interpolated SSTs issued from AMIP. It can be seen that the imposed temperature change of the idealized experiments is about twice as large as the scatter of the observed temperatures and that there is an offset of a few tenths of a degree between the two different SST data, which is not only due to the different time periods. It is not clear at present whether the lack of a relation is due to uncertainties in the observed SST data or to counteracting SST anomalies outside the equatorial Indian Ocean box.

The simulations are less conclusive over India for the western Pacific case. Whereas ECHAM and UGAMP simulate a dipole structure with increases in the southern part and decreases in the northern part for a warm western Pacific, ARPĖGE has reduced rainfall over most parts of India. The models at least agree on an intensification and northward shift of the tropical convective maximum for warm western Pacific SSTs as found in Soman and Slingo (1997).

The response to cold anomalies is also different in the three models. ARPÈGE is quite non-linear, in accordance with the findings of Hoerling et al. (1997). ECHAM, on the other hand, displays almost the same pattern with the opposite sign for cold anomalies as for warm ones. This disagreement is interpreted as a consequence of the different assumptions in the parameterizations of convection. As the triggering of convection and closure assumptions are among the controversial aspects of atmospheric models, no fast answer 

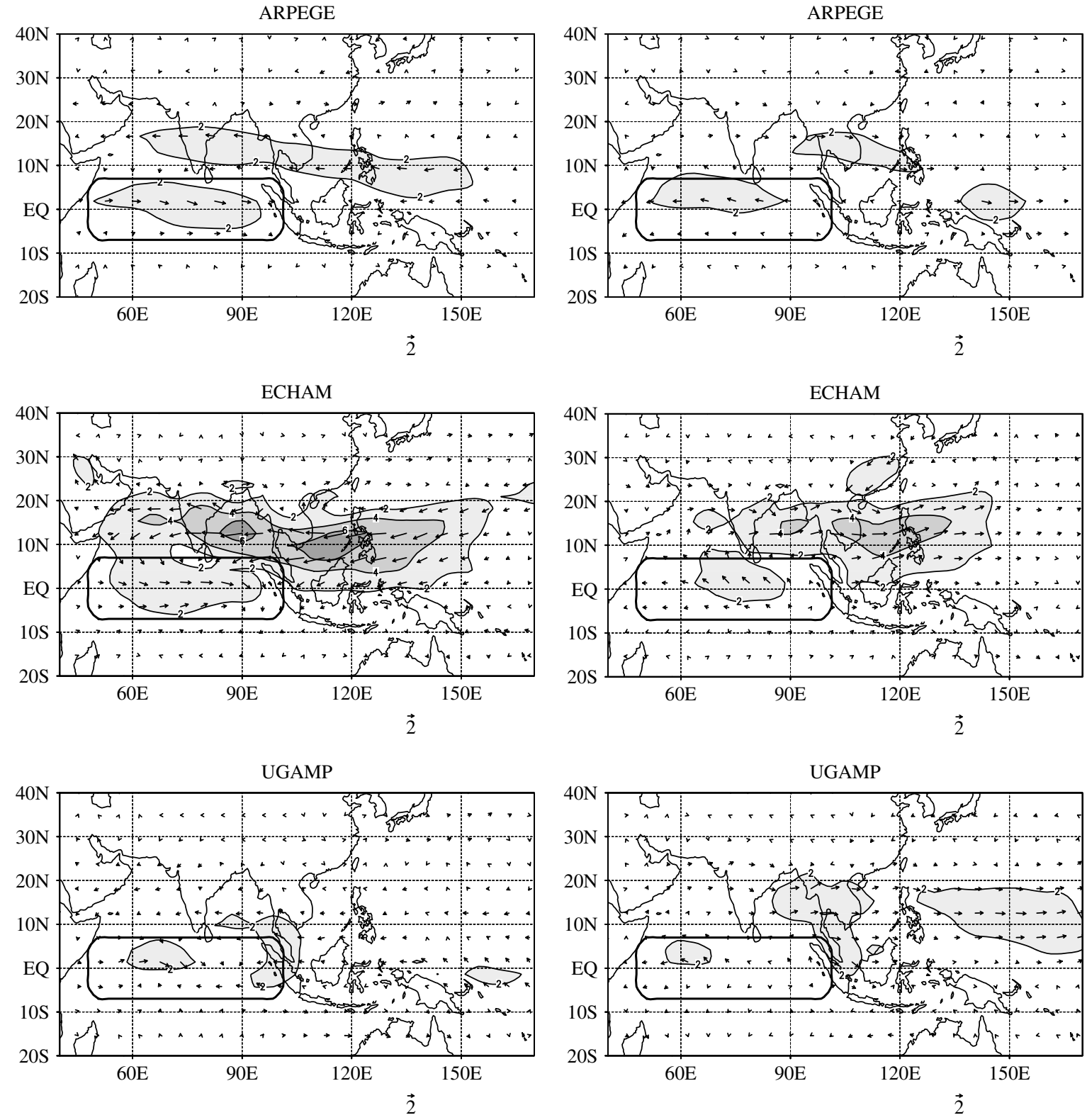

Figure 6. Wind anomalies at $850 \mathrm{hPa}$ for a $1 \mathrm{~K}$ warm (left)/cold (right) anomaly in the equatorial Indian Ocean. Wind speed anomalies shaded increasingly from $2 \mathrm{~m} \mathrm{~s}^{-1}$ onwards

can be expected on this issue. Further reductions of the systematic errors with regard to the simulation of the Asian monsoon are needed to achieve more consistent results between different models and, eventually, to obtain successful forecasts.

The experiments have shown that prescribed anomalies of $1 \mathrm{~K}$ have a significant impact on the strength of the Asian summer monsoon. The results indicate that the SST pattern in the vicinity of the monsoon countries has a large influence on the precipitation. This interpretation is also supported by additional experiments with ECHAM, where increased precipitation over India is found when the Arabian Sea and the Bay of Bengal are warmed by only $0.4 \mathrm{~K}$. Very accurate measurements of the SSTs in the Indian Ocean and western Pacific are thus needed to forecast the predictable part of the Asian summer monsoon. 


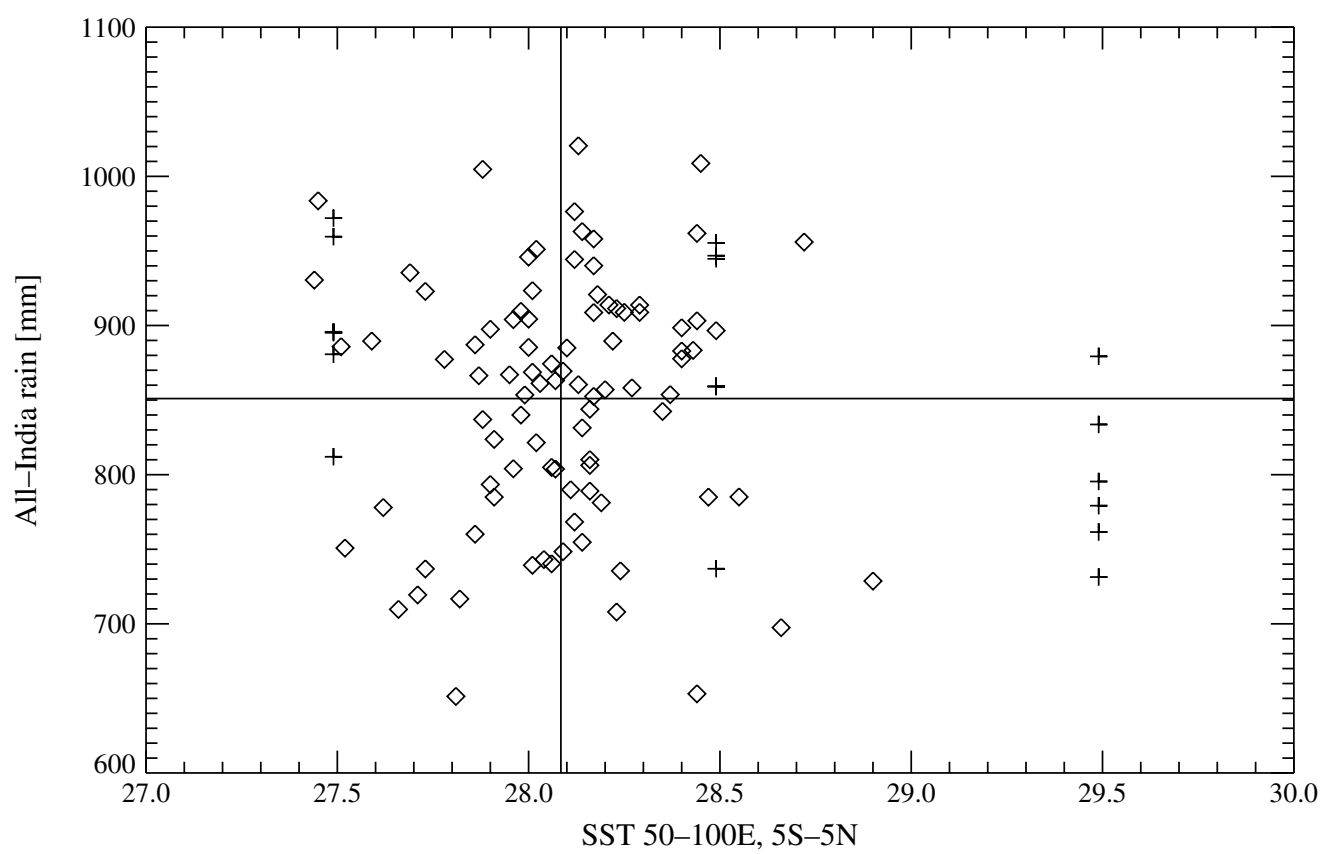

Figure 7. Observed AIR from Parthasarathy et al. (1994) against SST in the region $50-100^{\circ} \mathrm{E}, 5^{\circ} \mathrm{S}-5^{\circ} \mathrm{N}$. Each diamond corresponds to one of the years 1903 to 1994 of the GISST2.2 dataset. Ensemble members of the Indian Ocean simulations with ECHAM are also shown $(+)$

\section{ACKNOWLEDGEMENTS}

We thank the developers of the three models, in particular Dr M. Déqué and Dr E. Roeckner. The ECHAM simulations have been conducted on DKRZ resources. This work was funded by the European Union through the SHIVA project.

\section{REFERENCES}

Annamalai H, Slingo JM, Sperber KR, Hodges K. 1999. The mean evolution and variability of the Asian summer monsoon: comparison of ECMWF and NCEP/NCAR reanalyses. Monthly Weather Review 127: 1167-1186.

Arpe K, Dümenil L, Giorgetta MA. 1998. Variability of the Indian monsoon in the ECHAM3 model: sensitivity to sea surface temperature, soil moisture, and the stratospheric quasi-biennial oscillation. Journal of Climate 11: 1837-1858.

Betts AK, Miller MJ. 1993. The Betts-Miller scheme. In The Representation of Cumulus Convection in Numerical Models. Meteorological Monographs, Vol. 24, No. 46. American Meteorological Society: Boston, MA; 107-121.

Bougeault P. 1985. A simple parameterization of the large-scale effects of cumulus convection. Monthly Weather Review 113: $2108-2121$.

Chandrasekar A, Kitoh A. 1998. Impact of localized sea surface temperature anomalies over the equatorial Indian Ocean on the Indian summer monsoon. Journal of the Meteorological Society of Japan 76: 841-853.

Déqué M, Dreveton C, Braun A, Cariolle D. 1994. The ARPËGE/IFS atmospheric model: a contribution to the French community climate modelling. Climate Dynamics 10: 249-266.

Dong B-W, Valdes PJ. 1998. Modeling Asian summer monsooon rainfall and Eurasian winter/spring snow mass. Quarterly Journal of the Royal Meteorological Society 124: 2567-2596.

Gadgil S, Sajani S, PMG of AMIP. 1998. Monsoon precipitation in the AMIP runs. Climate Dynamics 14: 659-689.

Hoerling MP, Kumar A, Zhong M. 1997. El Niño, La Niña, and the nonlinearity of their teleconnections. Journal of Climate 10: 1769-1786.

Huffman GJ, Adler RF, Arkin P, Chang A, Ferraro R, Gruber A, Janowiak J, McNab A, Rudolf B, Schneider U. 1997. The Global Precipitation Climatology Project (GPCP) combined precipitation dataset. Bulletin of the American Meteorological Society 78: 5-20.

Palmer TN. 1994. Chaos and predictability in forecasting the monsoon. Proceedings of the Indian National Science Academy, Part A 60: $57-66$.

Parthasarathy B, Munot AA, Kothawale DR. 1994. All-India monthly and seasonal rainfall series: 1871-1993. Theoretical and Applied Climatology 49: 217-224.

Ricard J-L, Royer JF. 1993. A statistical cloud scheme for use in an AGCM. Annales Geophysicae 11: 1095-1115.

Rodwell MJ, Hoskins BJ. 1995. A model of the Asian summer monsoon. Part II: cross-equatorial flow and PV behavior. Journal of the Atmospheric Sciences 52: 1342-1356. 
Roeckner E, Arpe K, Bengtsson L, Christoph M, Claussen M, Dümenil L, Esch M, Giorgetta M, Schlese U, Schulzweida U. 1996. The atmospheric general circulation model ECHAM-4: model description and simulation of present-day climate. Technical Report 218, Max-Planck-Institut für Meteorologie.

Schulz J-P. 1998. On the role of the land surface representation and numerical coupling to the atmosphere for the simulated climate of the global ECHAM4 model. PhD thesis, Universität Hamburg (published as MPI Examensarbeit Nr. 57).

Slingo J, Blackburn M, Betts A, Brugge R, Hodges K, Hoskins B, Miller M, Steenman-Clark L, Thuburn J. 1994. Mean climate and transience in the tropics of the UGAMP GCM: sensitivity to convective parametrization. Quarterly Journal of the Royal Meteorological Society 120: $881-922$

Soman MK, Slingo J. 1997. Sensitivity of Asian summer monsoon to aspects of sea-surface-temperature anomalies in the tropical Pacific Ocean. Quarterly Journal of the Royal Meteorological Society 123: 309-336.

Sperber KR, Palmer TN. 1996. Interannual tropical rainfall variability in general circulation model simulations associated with the Atmospheric Model Intercomparison Project. Journal of Climate 9: 2727-2750.

Stendel M, Roeckner E. 1998. Impacts of horizontal resolution on simulated climate statistics in ECHAM4. Technical Report 253, Max-Planck-Institut für Meteorologie.

Stephenson DB, Chauvin F, Royer JF. 1998. Simulation of the Asian summer monsoon and its dependence on model horizontal resolution. Journal of the Meteorological Society of Japan 76: 237-265.

Tiedtke M. 1989. A comprehensive mass flux scheme for cumulus parameterization in large-scale models. Monthly Weather Review 117: $1779-1800$. 